\title{
Excellent outcomes after radiotherapy alone for malignant spinal cord compression from myeloma
}

\author{
Dirk Rades ${ }^{1}$, Antonio J. Conde-Moreno², Jon Cacicedo ${ }^{3}$, Barbara Segedin ${ }^{4}$, Volker Rudat ${ }^{5}$,
} Steven E. Schild 6

\author{
1 Department of Radiation Oncology, University of Lübeck, Lübeck, Germany \\ 2 Department of Radiation Oncology, Consorcio Hospital Provincial de Castellón, Castellón, Spain \\ ${ }^{3}$ Department of Radiation Oncology, Cruces University Hospital, Barakaldo, Vizcaya, Spain \\ ${ }^{4}$ Department of Radiotherapy, Institute of Oncology Ljubljana, Ljubljana, Slovenia \\ ${ }^{5}$ Department of Radiation Oncology, Saad Specialist Hospital Al Khobar, Saudi Arabia \\ ${ }^{6}$ Department of Radiation Oncology, Mayo Clinic, Scottsdale, AZ, USA
}

Radiol Oncol 2016; 50(3): 337-340.

Received 13 December 2015

Accepted 25 January 2016

Correspondence to: Prof. Dirk Rades, M.D., Department of Radiation Oncology, University of Lübeck, Ratzeburger Allee 160, 23538 Lübeck, Germany. Phone: +49 4515006 661; Fax: +49 4515003 324; E-mail: rades.dirk@gmx.net

Disclosure: No potential conflicts of interest were disclosed.

Background. Uncertainty exists whether patients with spinal cord compression (SCC) from a highly radiosensitive tumor require decompressive spinal surgery in addition to radiotherapy (RT). This study addressed the question by evaluating patients receiving RT alone for SCC from myeloma.

Patients and methods. Data of 238 patients were retrospectively analyzed for response to RT and local control of SCC. In addition, the effect of RT on motor function (improvement, no further progression, deterioration) was evaluated. Overall response was defined as improvement or no further progression of motor dysfunction. Prior to RT, patients were presented to a neurosurgeon for evaluation whether upfront decompressive surgery was indicated (e.g. vertebral fracture or unstable spine).

Results. In the entire cohort, the overall response rate was $97 \%$ (53\% improvement plus $44 \%$ no further progression). Following RT, $88 \%$ of the patients were able to walk. Of the 69 non-ambulatory patients 44 patients (64\%) regained the ability to walk. Local control rates at 1, 2 and 3 years were $93 \%, 82 \%$ and $82 \%$, respectively. A trend towards better local control was observed for patients who were ambulatory before starting RT $(p=0.08)$ and those with a more favorable performance status $(p=0.07)$.

Conclusions. RT alone provided excellent response rates, functional outcomes and local control in patients with SCC from myeloma. These results should be confirmed in a prospective randomized trial.

Key words: myeloma; spinal cord compression; radiotherapy alone; overall response; local control

\section{Introduction}

Myeloma patients account for about ten percent of patients presenting with malignant spinal cord compression (SCC). ${ }^{1}$ Radiotherapy (RT) alone is the most frequently used treatment for these patients worldwide. Ten years ago, a small randomized trial of 101 patients was published that compared
RT alone to decompressive surgery plus stabilization followed by RT in highly selected patients. ${ }^{2}$ In that trial the combined approach resulted in significantly better functional outcome (ambulation) and survival than irradiation alone. Therefore, upfront neurosurgery has become significantly more popular in several countries. Although patients with highly radiosensitive tumors such as myeloma, 


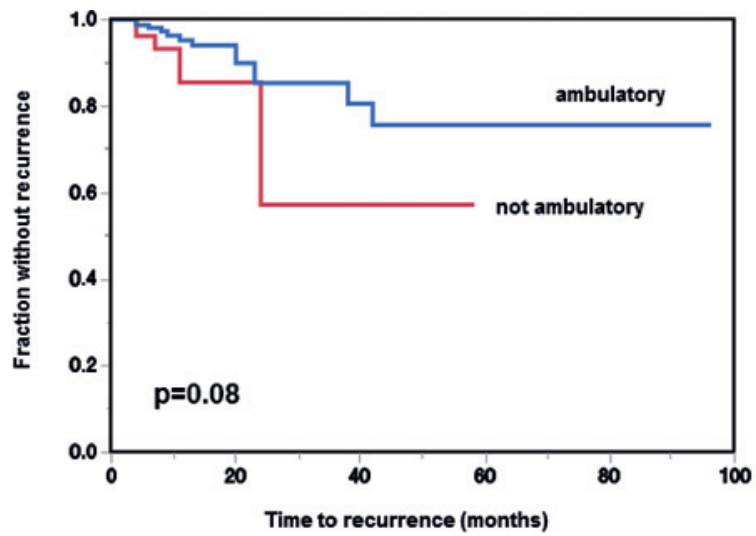

FIGURE 1. Kaplan-Meier curves of patients who were ambulatory prior to RT and of those patients who were not ambulatory.

lymphoma and germ cell tumors were excluded from the randomized trial of 101 patients, many neurosurgeons extrapolated from these findings and perform decompressive surgery in myeloma patients. ${ }^{2}$ The question remains whether RT alone is sufficient or needs to be supplemented by upfront decompressive surgery in malignant SCC from a highly radiosensitive tumor. This study aims to contribute to this open question by investigating overall response and local control of SCC in patients treated with RT alone for SCC from myeloma.

\section{Patients and methods}

Data of 238 patients presenting with motor deficits of the lower extremities in consequence of SCC from vertebral body myeloma were retrospectively analyzed. Prior to the start of RT, the patients were presented to a neurosurgeon for evaluation whether upfront decompressive surgery was indi-

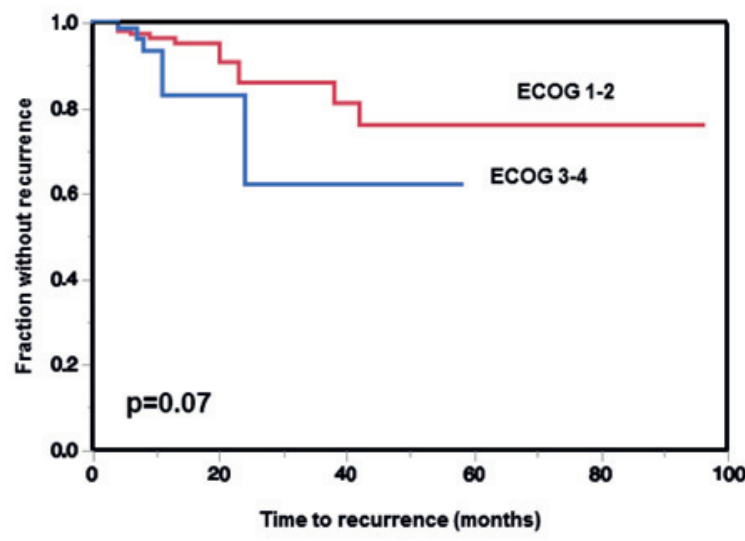

FIGURE 2. Kaplan-Meier curves of patients with an ECOG performance score of $1-2$ and those patients with an ECOG performance score of 3-4. cated, e.g. in case of vertebral body fracture, unstable spine or sphincter dysfunction. Patient who did not require surgery were included in this study.

RT was performed with 6-18 MV photon beams from a linear accelerator (mostly after 3D-treatment planning), and target volumes included the vertebrae affected by SCC plus on additional vertebra on either side. The study has been approved by the local ethics committee. For this retrospective study, specific written informed consent was not required.

The primary endpoint local control was defined as freedom from a symptomatic in-field recurrence of SCC in the irradiated parts of the vertebral column. In addition, the effect of radiation treatment on motor function (improvement, no further progression, deterioration) was measured. Improvement and deterioration of motor function were defined as a change of one point on a fivepoint scale $(0=$ normal strength; $1=$ ambulation without aid; 2 = ambulation with aid; $3=$ no ambulation; $4=$ complete paraplegia). ${ }^{3}$ Patients with complete paraplegia who did not improve after RT were rated as deteriorated. Motor function at about one month (three to six weeks) following RT was compared to motor function at baseline (i.e. before the start of RT Overall response to RT was defined as either improvement or no further progression of motor dysfunction.

RT was administered without upfront neurosurgery and performed either as short-course RT $(1 \mathrm{x}$ 8Gy, 5 x 4Gy) or longer-course RT (10 x 3Gy, 15 x $2.5 \mathrm{~Gy}, 20 \times 2 \mathrm{~Gy})$. The $\mathrm{RT}$ regimen plus ten other factors were analyzed for local control of SCC. The other factors included age at the time of RT $(\leq 64$ years $v s . \geq 65$ years, median age: 64 years), gender, myeloma subtype (IgG subtype vs. other subtypes), time from first diagnosis of myeloma to SCC $(\leq 15$ vs. $>15$ months), presence of extra-osseous lesions before RT (no vs. yes), further osseous lesions before RT (no vs. yes), gender, time developing motor deficits before RT (faster: $\leq 14$ vs. slower: $>14$ days), gait function before the start of RT (ambulatory vs. not ambulatory), number of vertebrae involved by SCC (1-2 vs. 2 3) and performance status (Eastern Cooperative Oncology Group (ECOG) performance score 1-2 vs. 3-4). The univariate analyses of local control of SCC were done with the KaplanMeier method ${ }^{4}$, and the Kaplan-Meier curves were compared with the log-rank test. Those factors being significant or showing a trend $(p<0.09)$ for local control were additionally analyzed in a multivariate manner with the Cox proportional hazards model. 
TABLE 1. Impact of the eleven factors on local control of SCC (univariate analysis)

\begin{tabular}{|c|c|c|c|c|}
\hline & $\begin{array}{c}\text { At } 1 \text { year } \\
(\%)\end{array}$ & $\begin{array}{c}\text { At } 2 \text { years } \\
(\%)\end{array}$ & $\begin{array}{c}\text { At } 3 \text { years } \\
(\%)\end{array}$ & $p$-value \\
\hline $\begin{array}{l}\text { Age } \\
\leq 64 \text { years }(n=125) \\
\geq 65 \text { years }(n=113)\end{array}$ & $\begin{array}{l}94 \\
92\end{array}$ & $\begin{array}{l}86 \\
75\end{array}$ & $\begin{array}{l}86 \\
75\end{array}$ & 0.81 \\
\hline $\begin{array}{l}\text { Gender } \\
\text { Female }(n=88) \\
\text { Male }(n=150)\end{array}$ & $\begin{array}{l}90 \\
94\end{array}$ & $\begin{array}{l}78 \\
85\end{array}$ & $\begin{array}{l}78 \\
85\end{array}$ & 0.47 \\
\hline $\begin{array}{l}\text { Myeloma subtype } \\
\text { IgG subtype }(n=153) \\
\text { Other subtypes ( } n=85)\end{array}$ & $\begin{array}{l}96 \\
88\end{array}$ & $\begin{array}{l}84 \\
78\end{array}$ & $\begin{array}{l}84 \\
78\end{array}$ & 0.14 \\
\hline $\begin{array}{l}\text { Time from myeloma diagnosis to SCC } \\
\leq 15 \text { months }(n=128) \\
>15 \text { months }(n=110)\end{array}$ & $\begin{array}{l}95 \\
91\end{array}$ & $\begin{array}{l}81 \\
85\end{array}$ & $\begin{array}{l}81 \\
85\end{array}$ & 0.83 \\
\hline $\begin{array}{l}\text { Extra-osseous lesions } \\
\text { No }(n=218) \\
\text { Yes }(n=20)\end{array}$ & $\begin{array}{l}94 \\
67\end{array}$ & $\begin{array}{c}82 \\
\text { n.a. }\end{array}$ & $\begin{array}{c}82 \\
\text { n.a. }\end{array}$ & 0.19 \\
\hline $\begin{array}{l}\text { Further osseous lesions } \\
\text { No }(n=91) \\
\text { Yes }(n=147)\end{array}$ & $\begin{array}{l}93 \\
93\end{array}$ & $\begin{array}{l}86 \\
76\end{array}$ & $\begin{array}{l}86 \\
76\end{array}$ & 0.73 \\
\hline $\begin{array}{l}\text { Time developing motor deficits } \\
\text { Faster }(\leq 14 \text { days) }(n=112) \\
\text { Slower }(>14 \text { days }=(n=126)\end{array}$ & $\begin{array}{l}93 \\
93\end{array}$ & $\begin{array}{l}81 \\
83\end{array}$ & $\begin{array}{l}81 \\
83\end{array}$ & 0.79 \\
\hline $\begin{array}{l}\text { Gait function before the start of RT } \\
\text { Ambulatory }(n=169) \\
\text { Not ambulatory }(n=69)\end{array}$ & $\begin{array}{l}95 \\
85\end{array}$ & $\begin{array}{l}85 \\
57\end{array}$ & $\begin{array}{l}85 \\
57\end{array}$ & 0.08 \\
\hline $\begin{array}{l}\text { Number of vertebrae involved by SCC } \\
1-2(n=112) \\
\geq 3(n=126)\end{array}$ & $\begin{array}{l}95 \\
92\end{array}$ & $\begin{array}{l}87 \\
77\end{array}$ & $\begin{array}{l}87 \\
77\end{array}$ & 0.17 \\
\hline $\begin{array}{l}\text { ECOG performance score } \\
1-2(n=150) \\
3-4(n=88)\end{array}$ & $\begin{array}{l}96 \\
83\end{array}$ & $\begin{array}{l}86 \\
62\end{array}$ & $\begin{array}{l}86 \\
62\end{array}$ & 0.07 \\
\hline $\begin{array}{l}\text { Radiotherapy regimen } \\
\text { Short-course RT }(n=84) \\
\text { Longer-course RT }(n=154)\end{array}$ & $\begin{array}{l}94 \\
93\end{array}$ & $\begin{array}{l}69 \\
90\end{array}$ & $\begin{array}{l}69 \\
90\end{array}$ & 0.29 \\
\hline Entire cohort $(n=238)$ & 93 & 82 & 82 & \\
\hline
\end{tabular}

n.a. $=$ not available

\section{Results}

Two-hundred-and-thirty-seven patients were available for evaluation of response to RT. The overall response rate at one month was $97 \%$ (230 of 237 patients); $53 \%$ of patients $(n=126)$ showed improvement and $44 \%(n=104)$ no further progression. Following RT, $88 \%$ of the patients (209 of 237) were able to walk. Of 69 non-ambulatory patients 44 patients $(64 \%)$ regained the ability to walk after RT.

In the entire cohort of 238 patients, the local control rates at 1, 2 and 3 years following RT of SCC were $93 \%, 82 \%$ and $82 \%$, respectively. In the univariate analysis, no factor was significantly associated with local control of SCC. A trend towards better local control was observed for patients who were ambulatory before RT was started $(p=0.08$, Figure 1) and for patients with a more favorable performance status ( $p=0.07$, Figure 2 ). These two factors were additionally evaluated in the multivariate analysis, where both pre-RT gait function (risk ratio: 2.34; 95\%-confidence interval: 0.80-6.10; $\mathrm{p}=0.11$ ) and performance status (risk ratio: 2.36; 95\%-confidence interval: $0.85-6.09 ; \mathrm{p}=0.09) \mathrm{did}$ not reach significance (significance $=$ defined as $\mathrm{p}$ $<0.05)$.

\section{Discussion}

Malignant SCC represents a serious complication for patients with a malignant disease. ${ }^{1,5} \mathrm{~A}$ rapid start of treatment is required. Until 2005, radiotherapy alone has been considered the unquestioned standard treatment for SCC. In 2005, a randomized trial of 101 selected patients with SCC from different primaries, who had a good performance status and a relatively good survival prognosis, suggested that the results of RT alone can be improved by upfront decompressive surgery. ${ }^{2}$ In that trial, $84 \%$ (42 of 50) of patients were able to walk after surgery plus RT compared to $57 \%$ (29 of 51) of patients 
after RT alone $(p=0.001)$. The results were supported by a meta-analysis including 24 surgical series $(n=999)$ and four radiotherapy series $(n=543)$, mostly uncontrolled cohort studies. ${ }^{6}$ These data have led to a fundamental change of practice. In several countries, neurosurgery proceeding RT has become very popular. In some centers, the majority patients with SCC receive the combined treatment rather than RT alone. This new trend includes also patients with highly radiosensitive tumors such as myeloma, although these patients were excluded from the previously mentioned randomized trial. ${ }^{2}$ The question is whether these patients really need surgery in addition to RT? One should bear in mind that spinal surgery is associated with significant risks and complications such as severe wound infections. A second surgery, extensive bleeding, postoperative pneumonia, and major thromboembolic events occurred in more than $10 \%$ of patients. $2,7,8$ In addition, iatrogenic neurologic complications were reported for $9 \%$ of patients receiving surgery of the lumbar spine. ${ }^{9}$

In the current study, functional outcomes were excellent with a post-RT overall ambulation rate of $88 \%$ and a rate of regaining ambulatory status of $64 \%$. Furthermore, local control of SCC achieved with RT alone was long lasting. At 3 years following RT, local control was still $82 \%$. These excellent local control rates were achieved irrespectively of patient characteristics. None of the eleven investigated characteristics was significantly associated with local control of SCC. However, pre-RT gait function and performance status showed a trend. Three-year local control rates were $57 \%$ in initially non-ambulatory patients and $62 \%$ in patients with an ECOG performance score of 3-4, respectively. The question whether these patients would benefit from the addition of upfront decompressive surgery to RT can be properly answered only in a prospective trial. Clear indications for neurosurgery also for very radiosensitive tumors include vertebral fractures, unstable spine, sphincter dysfunction, and impairment of the spinal cord by bony fragments. According to a recent retrospective study focusing on surgery for vertebral involvement of myeloma, the probability of receiving surgery was about $40 \%{ }^{10}$ No differences in disability and quality of life were observed between patients receiving RT alone and those receiving RT plus upfront surgery. For highly selected patients, stereotactic body radiation surgery (SBRT) may also be an option. ${ }^{11,12}$ However, it has been recommended to use SBRT for malignant SCC only within clinical trials. $^{12}$
In summary, in patients with malignant SCC from myeloma, RT alone provides excellent response rates, functional outcomes such as post-RT ambulation, and local control of SCC. These results should be confirmed in a prospective randomized trial.

\section{References}

1. Rades $\mathrm{D}, \mathrm{Abrahm} \mathrm{JL}$. The role of radiotherapy for metastatic epidural spinal cord compression. Nat Rev Clin Oncol 2010; 7: 590-8.

2. Patchell R, Tibbs PA, Regine WF, Payne R, Saris S, Kryscio RJ, et al. Direct decompressive surgical resection in the treatment of spinal cord compression caused by metastatic cancer: a randomised trial. Lancet 2005; 366: 643-8.

3. Tomita T, Galicich JH, Sundaresan N. Radiation therapy for spinal epidural metastases with complete block. Acta Radiol Oncol 1983; 22: 135-43.

4. Kaplan EL, Meier P. Non parametric estimation from incomplete observations. J Am Stat Assoc 1958; 53: 457-81.

5. Rades D, Huttenlocher S, Bajrovic A, Karstens JH, Bartscht T. A new instrument for estimating the survival of patients with metastatic epidural spinal cord compression from esophageal cancer. Radiol Oncol 2015; 49: 86-90.

6. Klimo P Jr, Thompson CJ, Kestle JR, Schmidt MH. A meta-analysis of surgery versus conventional radiotherapy for the treatment of metastatic spinal epidural disease. Neuro Oncol 2005; 7: 64-76.

7. Rades D, Huttenlocher S, Bajrovic A, Karstens JH, Adamietz IA, Kazic N, et al. Surgery followed by radiotherapy versus radiotherapy alone for metastatic spinal cord compression from unfavorable tumors. Int J Radiat Oncol Biol Phys 2011; 81: e861-8.

8. Rades D, Huttenlocher S, Dunst J, Bajrovic A, Karstens JH, Rudat V, et al. Matched pair analysis comparing surgery followed by radiotherapy and radiotherapy alone for metastatic spinal cord compression. J Clin Oncol 2010; 28: 3597-604.

9. Ghobrial GM, Williams KA Jr, Arnold P, Fehlings M, Harrop JS. latrogenic neurologic deficit after lumbar spine surgery: A review. Clin Neurol Neurosurg 2015; 139: 76-80.

10. Donnarumma P, Tarantino R, Rullo M, Grisaro A, Petrucci MT, Santoro A, Delfini R. Surgery for vertebral involvement in multiple myeloma. J Neurosurg Sci 2015; in press.

11. Lee SH, Lee KC, Choi J, Ahn SH, Lee SH, Sung KH, et al. Clinical applicability of biologically effective dose calculation for spinal cord in fractionated spine stereotactic body radiation therapy. Radiol Oncol 2015; 49: 185-91.

12. Lutz S, Berk L, Chang E, Chow E, Hahn C, Hoskin P, et al. Palliative Radiotherapy for Bone Metastases: An ASTRO Evidence-Based Guideline. Int J Radiat Oncol Biol Phys 2011; 79: 965-76. 